\title{
Microstructure characterization and SCG of newly engineered dental ceramics
}

\author{
Nathália de Carvalho Ramos ${ }^{a}$, Tiago Moreira Bastos Campos ${ }^{b}$, \\ Igor Siqueira de La Paz ${ }^{a}$, João Paulo Barros Machadoc, \\ Marco Antonio Bottino ${ }^{a}$, Paulo Francisco Cesar ${ }^{d}$, \\ Renata Marques de Melo ${ }^{a, *}$
}

a Department of Dental Materials and Prosthodontics, São Paulo State University (UNESP), Institute of Science and Technology, 777 Eng. Francisco José Longo Avenue, 12245-000, São José dos Campos, SP, Brazil

b Aeronautics Technological Institute (ITA), 50 Praça Marechal Eduardo Gomes, 12228-900, São José dos Campos, SP, Brazil

c National Institute for Space Research, Associated Laboratory of Sensors and Materials, 1758 Astronautas Avenue, 12217-010, São José dos Campos, SP, Brazil

d University of São Paulo (USP), School of Dentistry, Department of Biomaterials and Oral Biology, 2227 Prof. Lineu Prestes Avenue, 05508-000, São Paulo, SP, Brazil

\section{A R T I C L E I N F O}

\section{Article history:}

Received 8 June 2015

Received in revised form

23 November 2015

Accepted 22 March 2016

Keywords:

Ceramics

Dental porcelain

Glass ceramics

Subcritical crack growth

Stress corrosion

Computer-aided design

Flexural strength

Young's modulus

Spectroscopy

\section{A B S T R A C T}

Objectives. The aim of this study was to characterize the microstructure of four dental CADCAM ceramics and evaluate their susceptibility to stress corrosion.

Methods. SEM and EDS were performed for microstructural characterization. For evaluation of the pattern of crystallization of the ceramics and the molecular composition, XRD and FTIR, respectively, were used. Elastic modulus, Poisson's ratio, density and fracture toughness were also measured. The specimens were subjected to biaxial flexure under five stress rates $(0.006,0.06,0.6,6$ and $60 \mathrm{MPa} / \mathrm{s})$ to determine the subcritical crack growth parameters $(n$ and $D)$. Twenty-five specimens were further tested in mineral oil for determination of Weibull parameters. Two hundred forty ceramic discs (12 $\mathrm{mm}$ diameter and $1.2 \mathrm{~mm}$ thick) were made from four ceramics: feldspathic ceramic - FEL (Vita Mark II, Vita Zahnfabrik), ceramic-infiltrated polymer - PIC (Vita Enamic, Vita Zahnfabrik), lithium disilicate - LD (IPS e.max CAD, Ivoclar Vivadent) and zirconia-reinforced lithium silicate - LS (Vita Suprinity, Vita Zahnfabrik).

Results. PIC discs presented organic and inorganic phases $(n=29.1 \pm 7.7)$ and Weibull modulus $(m)$ of 8.96. The FEL discs showed $n=36.6 \pm 6.8$ and $m=8.02$. The LD discs showed a structure with needle-like disilicate grains in a glassy matrix and had the lowest value of $n(8.4 \pm 0.8)$ and $m=6.19$. The ZLS discs showed similar rod-like grains, $n=11.2 \pm 1.4$ and $m=9.98$.

Significance. The FEL and PIC discs showed the lowest susceptibility to slow crack growth (SCG), whereas the LD and ZLS discs presented the highest. PIC presented the lowest elastic

\footnotetext{
* Corresponding author at: Av. Engenheiro Francisco José Longo, 777, 12245-200, São Dimas, São José dos Campos, SP, Brazil. Tel.: +55 1239479032 .

E-mail addresses: renata.marinho@ict.unesp.br, marquesdemelo@gmail.com (R.M.d. Melo). http://dx.doi.org/10.1016/j.dental.2016.03.018 0109-5641/@ 2016 The Academy of Dental Materials. Published by Elsevier Ltd. All rights reserved.
} 
modulus and no crystals in its composition, while ZLS presented tetragonal zirconia. The overall strength and SCG of the new materials did not benefit from the additional phase or microconstituents present in them.

(c) 2016 The Academy of Dental Materials. Published by Elsevier Ltd. All rights reserved.

\section{Introduction}

New indirect restorative materials have been recently released in the dental market based on different microstructural approaches in comparison with those of previously available indirect materials. One example of these innovative materials is a polymer-infiltrated ceramic (PIC) CAD-CAM block that is claimed to have higher structural reliability as a result of the so-called crack-stop function mechanism, which occurs when a crack that is propagating through the polymer network halts due to the presence of the ceramic phase. Recent publications showed that this type of material is composed of a polymer-infiltrated ceramic network containing urethane dimethacrylate (UDMA) and triethylene glycol dimethacrylate (TEGDMA) cross-linked polymers [1]. In comparison with dental porcelains, this new material has been proven to have lower elastic modulus and higher damage tolerance [2].

Another recently released indirect dental material is a lithium-silicate-based glass-ceramic reinforced with zirconia particles (ZLS). According to the manufacturer, the zirconia particles added to this glass-ceramic are small and homogeneously distributed throughout the microstructure, improving its strength and providing good surface finish. This material is provided only for CAD-CAM technology, and, to the authors' knowledge, no laboratory or clinical data have yet been published regarding this product. The microstructure of this new glass-ceramic material is similar to that seen in lithium disilicate ceramics, which, for many years, were protected by a patent held by Ivoclar Vivadent and became well-known for their excellent optical properties [3]. These lithium disilicate ceramics are now commercially available as pressable ingots or CAD-CAM blocks, the latter having an intermediate stage of crystallization that, after milling, still requires heat treatment for crystal growth.

Ceramic restorations are constantly subjected to humidity and occlusal loads, and their time in service is controlled by slow crack growth (SCG), which is the environmentally assisted subcritical growth of cracks. SCG can be estimated by a power law relation in which a coefficient, $n$, expresses the material's susceptibility to stable crack growth. The higher the value of $n$, the lower the susceptibility to SCG. The method commonly used for measuring the subcritical crack growth parameter is the constant-stress-rate test, in which the material strength is obtained as a function of various stress rates in a certain environment [6].

The development of newly engineered indirect materials has led to a need for new studies to characterize their mechanical and fatigue properties, in attempts to predict their clinical behavior. Therefore, the primary objective of the
Table 1 - Cycle of crystallization of LD and ZLS ceramics.

\begin{tabular}{lcc} 
& $\begin{array}{c}\text { ZLS (Vita } \\
\text { Suprinity) }\end{array}$ & $\begin{array}{c}\text { LD (IPS } \\
\text { e.max CAD) }\end{array}$ \\
\hline $\begin{array}{l}\text { Beginning chamber } \\
\text { temperature }\left({ }^{\circ} \mathrm{C}\right)\end{array}$ & 400 & 403 \\
$\begin{array}{l}\text { Time at the initial temperature } \\
(\mathrm{min})\end{array}$ & $8: 00$ & $6: 00$ \\
$\begin{array}{l}\text { Temperature rate increase } \\
\left({ }^{\circ} \mathrm{C} / \text { min }\right)\end{array}$ & 55 & 90 \\
$\begin{array}{l}\text { Crystallization temperature } \\
\left({ }^{\circ} \mathrm{C}\right)\end{array}$ & 840 & 820 \\
$\begin{array}{l}\text { Holding time }(\min ) \\
\text { Ending temperature }\left({ }^{\circ} \mathrm{C}\right)\end{array}$ & $8: 00$ & $7: 00$ \\
\hline
\end{tabular}

present study was to characterize the microstructure and the slow crack growth (fatigue) parameters using constant-stressrate testing of the following indirect restorative materials: polymer-infiltrated (PIC), zirconia-reinforced lithium silicate (ZLS), lithium disilicate (LD) and feldspathic (FEL) ceramics, all designed for CAD-CAM processing. Also, fracture toughness, elastic modulus and Weibull parameters were determined.

\section{Materials and methods}

Sixty discs of each of the following materials were prepared: feldspathic ceramic (Vita Mark II, Vita Zahnfabrik, Bad Säckingen, Germany), polymer-infiltrated ceramic (Vita Enamic, Vita Zahnfabrik), lithium disilicate ceramic (IPS e.max CAD, Ivoclar Vivadent, Schaan, Liechtenstein) and zirconia-reinforced lithium silicate ceramic (Vita Suprinity, Vita Zahnfabrik).

\subsection{Specimen preparation}

A ring device was glued onto the top surfaces of the CADCAM blocks to round them until cylinders $12 \mathrm{~mm}$ in diameter were obtained. The cylinders were then cut into several discs approximately $12 \mathrm{~mm}$ in diameter and $1.35 \mathrm{~mm}$ thick, in a lathe (ISOMET 1000, Buehler, Lake Bluff, IL, USA). IPS e.max CAD and Vita Suprinity require a cycle of crystallization that was performed in their respective furnaces (Programat EP5000, Ivoclar Vivadent; and Vita Vacumat 6000MP, Vita Zahnfabrik) according to the temperature recommendations given by the manufacturers (Table 1). The specimens were then polished with SiC\#400, 800 and 1200. According to ISO standard CD 6872, specimens attained final dimensions of $12 \mathrm{~mm}$ in diameter and $1.2 \mathrm{~mm}$ thick [4]. 


\subsection{Elastic modulus and fracture toughness determination}

The determination of the elastic modulus of the material was performed by the pulse-echo method with pulse receiver equipment (MOD 5900 PR, Olympus, Center Valley, PA, USA) connected to an oscilloscope (TDS 1002, Tektronix, Beaverton, OR, USA). The density of each material was measured by the Archimedes method in a precision balance by measurement of the dry mass of the specimens and then measurement of the volume of water displaced when the specimens were put into the water. The formula for calculation of the elastic modulus was:

$E=\rho\left(\frac{3 V_{t}^{2} V_{l}^{2}-4 V_{t}^{4}}{V_{l}^{2}-V_{t}^{2}}\right)$

where $\rho$ is density, and $V_{t}$ and $V_{l}$ are the longitudinal and transverse wave velocities, respectively.

Fracture toughness determination was based on a description of surface cracks in disks in flexure experiments conducted by Strobl et al. [5]. First, Knoop indentations were performed on three discs of each material, to create a controlled superficial defect. Samples were indented with $19.61 \mathrm{~N}$ loading for $12 \mathrm{~s}$. The samples were then polished with $\mathrm{SiC} \# 800$ for removal of the residual stress $(\sim 3-5 \mu \mathrm{m})$.

After being polished, the specimens were fractured under biaxial flexure at a speed of $0.5 \mathrm{~mm} / \mathrm{min}$ in mineral oil. We then measured the defect depth and surface extension on the fracture surfaces, using a stereomicroscope (Discovery V20, Carl Zeiss, Jena, Germany) at a magnification of $100 \times$, and determined fracture toughness $\left(\mathrm{K}_{\mathrm{IC}}\right)\left(\mathrm{MPa} \mathrm{m}^{1 / 2}\right)$ according to the equation:

$K_{\mathrm{Ic}}=\sigma_{\mathrm{B} 3 \mathrm{~B}} Y \sqrt{a \pi}$

where $\sigma_{\mathrm{B} 3 \mathrm{~B}}$ is the strength with the ball in the three-ball method (an interactive Web-Mathematica tool can be found at http://www.isfk.at/en/960/), Y is a geometric factor as a function of the crack shape and the relative crack depth obtained by calculations from Strobl et al. and $a$ is the crack depth [5].

The measured properties (elastic modulus and fracture toughness) were analyzed statistically by one-way ANOVA and Tukey's post-hoc test $(p<0.05)$.

\subsection{Constant-stress-rate testing and Weibull analysis}

The constant-stress-rate testing for determination of SCG parameters, $n$ and $D$, was performed at five rates in water: $0.006,0.06,0.6,6$ and $60 \mathrm{MPa} / \mathrm{s}$. The numbers of specimens per rate were 10 for the extreme values and 5 for the three intermediate rates. The parameters $n$ and $D$ were determined by a linear regression analysis, according to the following equation [6]:

$\log \sigma_{f}=\frac{1}{n+1} \log \dot{\sigma}+\log D$

where $\sigma_{f}$ is the mean strength (MPa) and $\dot{\sigma}$ is the stress rate (MPa/s).

The inert strength was obtained in an inert environment (mineral oil) under the highest stress rate $(60 \mathrm{MPa} / \mathrm{s})$. These results were subjected to Weibull statistical analysis by the maximum likelihood method.

The piston-on-three-ball biaxial flexure experiment for performing constant-stress-rate testing and inert strength measurements was carried out in a universal testing machine with $500 \mathrm{kgf}$ cell loading. The strength calculations were based on the following equation:

$\sigma=-0.2387 \mathrm{P} \frac{(\mathrm{X}-\mathrm{Y})}{b^{2}}$

where $P$ is the load in $\mathrm{kgf}, \mathrm{X}$ and $\mathrm{Y}$ are parameters related to the elastic properties of the material (Poisson's ratio and elastic modulus) and $b$ is the specimen thickness at the fracture origin in $\mathrm{mm}$.

2.4. Scanning electron microscopy (SEM), energy-dispersive spectroscopy (EDS), X-ray diffraction (XRD) and Fourier transformed infra-red (FTIR) analyses

SEM analyses were performed on polished specimens following several surface-conditionings with hydrofluoric acid until the various phases could be distinguished. The acid concentrations and conditioning times varied according to the material. In addition, the reinforced polymer-ceramic was fired to $600^{\circ} \mathrm{C}$ for $5 \mathrm{~h}$ and kept at this temperature for $5 \mathrm{~h}$ to ensure complete removal of the polymer. The specimens were examined in a scanning electron microscope with a highresolution emission field (Magellan 400L, FEI Company, Brno, Czech Republic) so that the shapes and sizes of the grains could be observed. The chemical analysis of the microconstituents was performed by EDS (Bruker Nano GmbH, Berlin, Germany).

X-ray diffraction (Model X'pert Powder, PANalytical, Almelo, Netherlands) was also performed with the database software X'Pert High Score (PANalytical) for two specimens from each group, to visualize the pattern of crystallization.

For the polymer-infiltrated ceramic, vibrational spectroscopy was also performed by FTIR to determine the molecular composition of the organic and inorganic components of this material.

\section{Results}

\subsection{Microstructural characterization}

The results obtained from the X-ray diffraction analysis are displayed in Fig. 1. IPS e.max CAD (LD) showed crystallization peaks corresponding to lithium disilicate ( $\mathrm{ds}-\mathrm{Li}_{2} \mathrm{O}_{5} \mathrm{Si}_{2}$ ). Vita Suprinity (ZLS) showed peaks corresponding to lithium monosilicate ( $\mathrm{ms}-\mathrm{Li}_{2} \mathrm{O}_{3} \mathrm{Si}$, and $\mathrm{ls}-\mathrm{Li}_{8} \mathrm{O}_{6} \mathrm{Si}$ ), aluminum silicate (als - $\mathrm{Al}_{0.5} \mathrm{O}_{2.25} \mathrm{Si}_{0.75}$ ) and tetragonal zirconia ( $\mathrm{zr}$ $\mathrm{O}_{2} \mathrm{Zr}_{0.952}$ ). Vita Mark II (FEL) showed two crystallization patterns, with peaks identified as "a" and "b", with "a" being a sodium potassium aluminum silicate peak $\left(\mathrm{Al}_{8} \mathrm{~K}_{2} \mathrm{Na}_{6} \mathrm{O}_{3} 4 \mathrm{Si}_{9}\right)$ and " $\mathrm{b}$ " being a potassium sodium aluminum silicate peak $\left(\mathrm{AlK}_{0.29} \mathrm{Na}_{0.71} \mathrm{O}_{8} \mathrm{Si}_{3}\right)$. The polymer-infiltrated ceramic was found to be amorphous (both phases), with no evidence of crystallization.

Table 2 shows the chemical constituents of each studied material. As expected, lithium could not be identified in any 


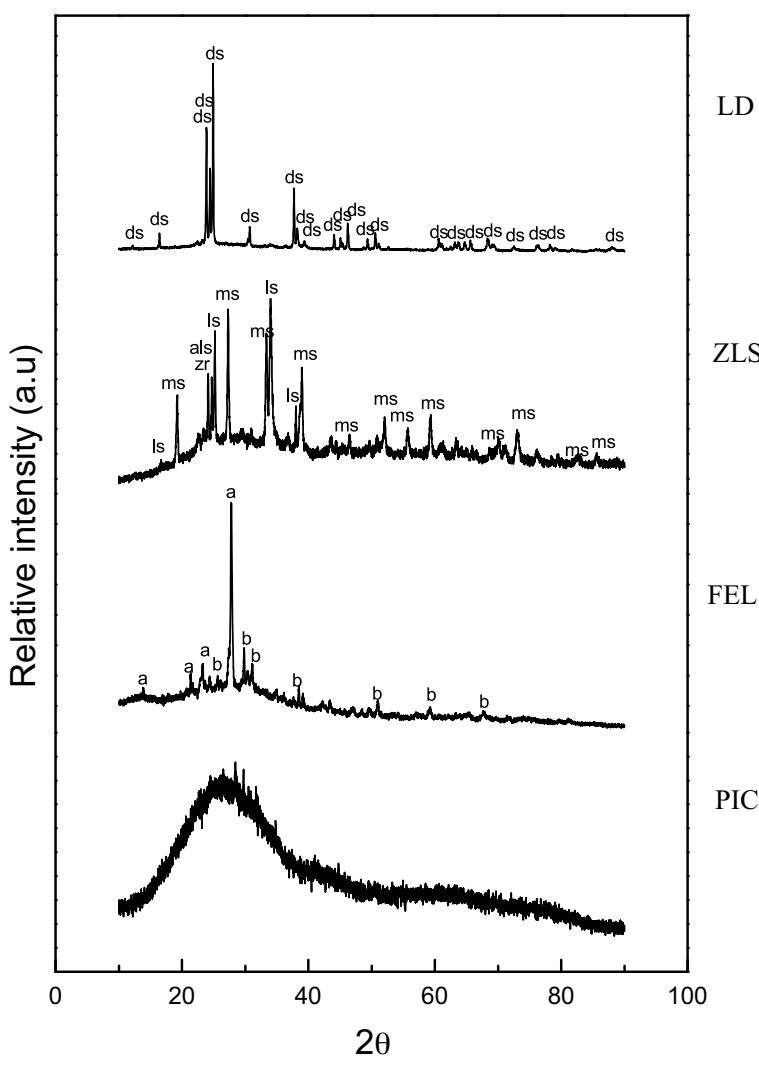

Fig. 1 - XRD spectra: (LD) lithium disilicate, (ZLS) lithium silicate reinforced by zirconia, (FEL) feldspathic ceramic and (PIC) polymer-infiltrated ceramic.

of the analyzed materials. Oxygen, silicon, aluminum, and potassium were detected in all materials, whereas sodium appeared only in PIC and FEL. Noteworthy are the percentages of carbon ( $15 \%)$ and zirconia $(\sim 21 \%)$ in PIC and ZLS, respectively, and also the fact that carbon was not totally eliminated after PIC was fired.

Fig. 2 shows the vibration spectra (FTIR) of the polymerreinforced ceramic. The letters at the top indicate the different bands, which are further explained in Table 3. These bands indicate the presence of tetra-coordinated aluminum and silicon in this composite. The XRD analysis indicated that although the composition of the amorphous ceramic phase is similar to that of feldspathic ceramics, only the latter contain leucite as a crystalline phase. Still in Fig. 2, one can see that bands $F, G, H$, and I refer to the inorganic component, with

\begin{tabular}{|c|c|c|c|c|c|}
\hline Ceramics & FEL & PIC & PIC fired & ZLS & LD \\
\hline Oxygen & 46.3 & 41.6 & 46.4 & 51.2 & 54.3 \\
\hline Silicon & 20.1 & 18.5 & 26.3 & 29.6 & 39.3 \\
\hline Carbon & - & 21.2 & 4.4 & - & - \\
\hline Zirconia & - & - & - & 15.5 & - \\
\hline Aluminum & 13.3 & 9.3 & 11.4 & 1.3 & 2.3 \\
\hline Sodium & 6.6 & 4.7 & 6.0 & - & - \\
\hline Potassium & 6.4 & 4.5 & 5.2 & 2.3 & 4.0 \\
\hline
\end{tabular}

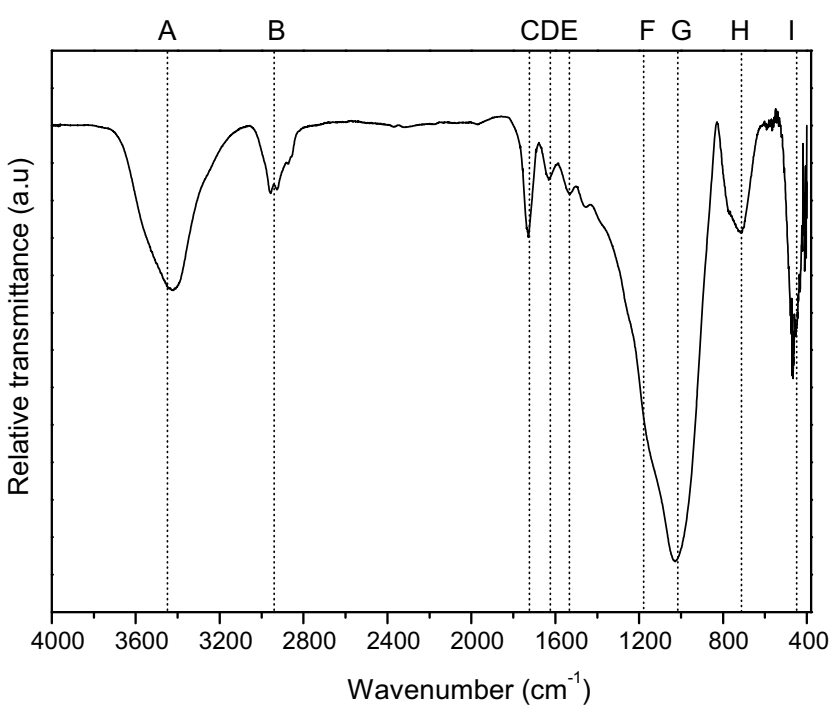

Fig. 2 - FTIR spectrum of the polymer-infiltrated ceramic.

F and $G$ bands corresponding to tetrahedral aluminum and tetrahedral silica. This material did not show bands related to octahedral aluminum. The organic fraction of this polymerreinforced ceramic is represented by bands $A, B, C, D$ and $E$. " $\mathrm{A}$ " is related to the stretching of the $\mathrm{N}-\mathrm{H}$ bonds, and " $\mathrm{B}$ " refers to $\mathrm{C}-\mathrm{H}$ bonds, symmetric and asymmetric stretches of carboxylic groups. "C" and " $\mathrm{D}$ " are carbonyl bands corresponding to the polymeric network. Bands " $C$ " and " $D$ " are most likely related to the vibrations of urethane dimethacrylate (UDMA) and triethylene glycol dimethacrylate (TEGDMA) [7].

Specimens of the polymer-reinforced ceramic were observed under Scanning Electron Microscope with Field Emission Gun (SEM-FEG, JEOL 7500-F, Peabody, MA, USA) for microstructural characterization (Fig. 3). These micrographs showed the presence of two phases (Fig. 3A). Mapping with EDS was carried out to characterize regions corresponding to ceramic and polymer (Fig. 3B). Fig. 3 also shows micrographs of the polymer-reinforced ceramic after being etched with hydrofluoric acid (Fig. 3C) and after the polymeric network was removed when the material was heated (Fig. 3D).

Table 3 - Assignment of the FTIR bands of the polymer-infiltrated ceramic.

\begin{tabular}{llc} 
Wavenumber $\left(\mathrm{cm}^{-1}\right)$ & \multicolumn{1}{c}{ Assignment } & Band \\
\hline 3432 & $\begin{array}{l}\text { Stretching }(-\mathrm{NH}) \\
\text { nto }(-\mathrm{OH})\end{array}$ & A \\
& Stretching (CH) & B \\
2912 & Stretching (C=O) & C \\
1730 & Stretching (C=O) & D \\
1617 & Amide & E \\
1530 & Asymmetric stretching & F \\
1070 & (Si-O-Si and Si-O-Al) & \\
1058 & $\begin{array}{l}\text { Asymmetric stretching } \\
\text { (Si-O-Si and Si-O-Al) }\end{array}$ & G \\
792 & Tetracoordinated Al-O & H \\
469 & stretching & I \\
\hline
\end{tabular}



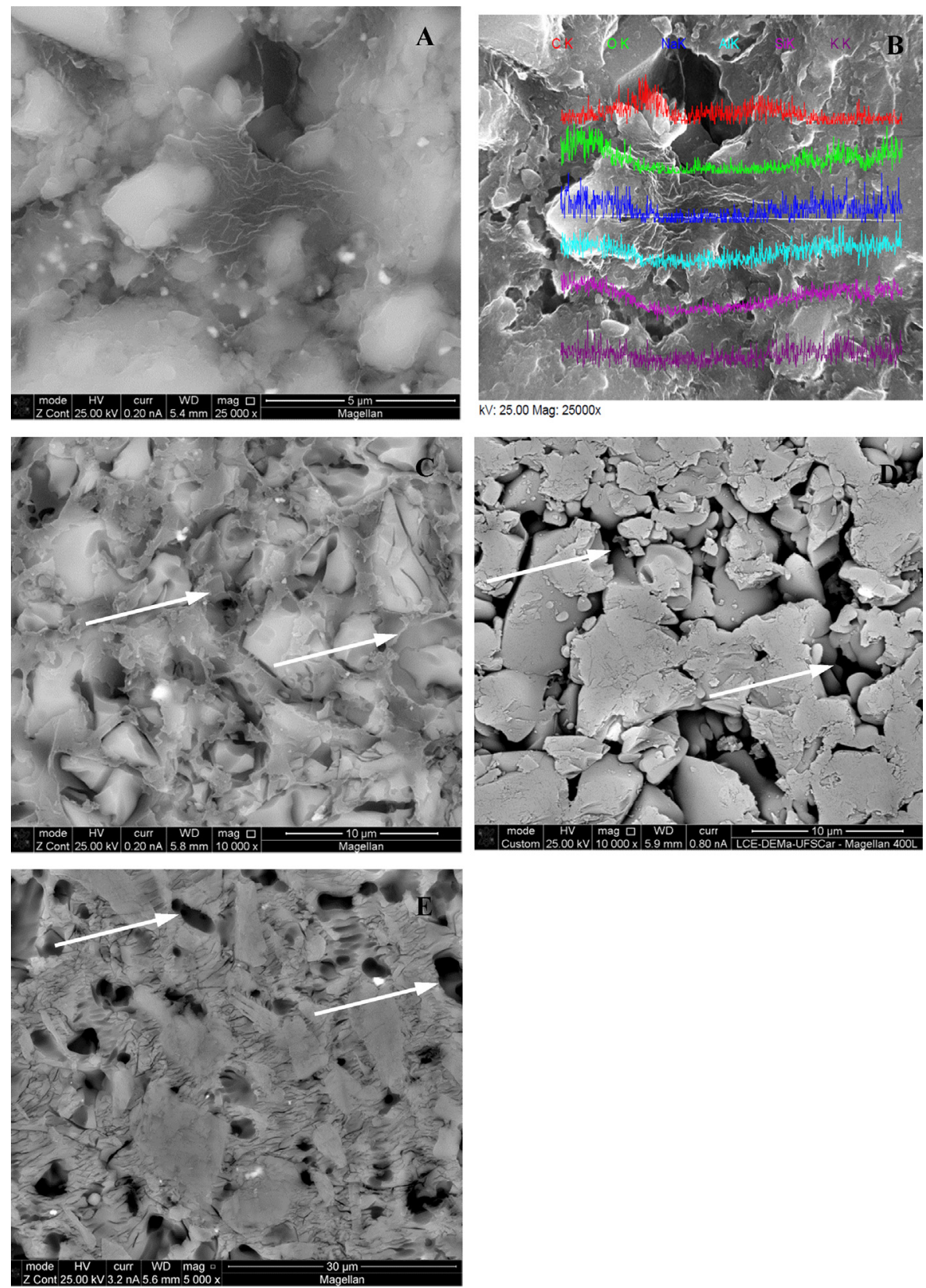

Fig. 3 - Micrographs of PIC and FEL. (A) PIC without acid etching. (B) EDS mapping, where the red line is the carbon (polymer) content. (C) PIC etched with $5 \%$ HF for 20 s, where arrows show the polymer net. (D) PIC after firing, with arrows indicating the empty spaces after the polymer removal. (E) FEL etched with $5 \% \mathrm{HF}$ for $20 \mathrm{~s}$, with arrows showing the holes caused by the dissolution of the glassy matrix.(For interpretation of the references to color in this figure legend, the reader is referred to the web version of the article.)

The microstructure of the feldspathic ceramic after acidetching is shown in Fig. 3E. It can be seen that this is a single-phase and very porous material. Fig. 4 depicts the microstructure of both the lithium disilicate (LD) and zirconiareinforced lithium silicate ceramics (ZLS). Fig. 4A shows that the lithium disilicate crystals in LD were acicular; after hydrofluoric acid-etching, the same crystals appeared larger and more elongated (Fig. 4B). The lithium silicate crystals in ZLS could not be observed without etching. After etching, it was noted that these crystals were slightly larger and more rounded compared with the disilicate crystals, with a rodlike appearance (Fig. 4C). Some heavily charged zones (Fig. 4D) were analyzed by EDS, and showed composition similar to that of the non-charged zones, leading to rejection of the hypothesis that zirconia particles were concentrated in these areas. Conversely, zirconium oxide and cerium (a stabilizing agent of tetragonal zirconia) were identified throughout the entire surface of ZLS. 

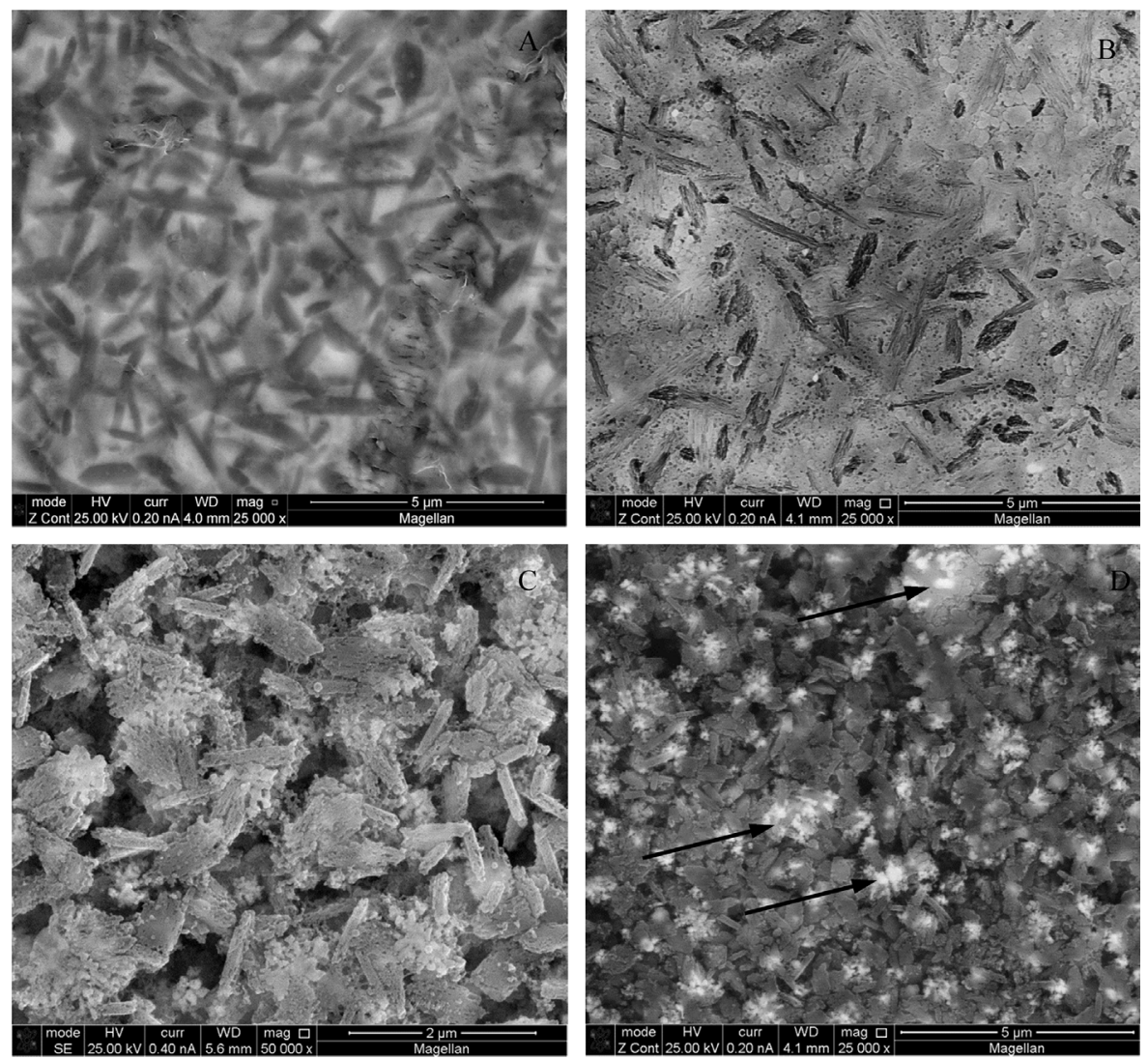

Fig. 4 - LD and ZLS microstructures. (A) LD without etching and (B) etched with $5 \%$ HF for 20 s, showing needle-like crystals (C and D), and ZLS etched with $5 \%$ HF for 20 s, showing rod-like crystals and charged areas (arrows) with the same composition as that of the non-charged areas. In comparison of the etched surfaces of B and D (same magnifications), one can see that the LD crystals are larger than the ZLS crystals, which are finer structures.

\subsection{Measured properties, SCG and Weibull parameters}

Table 4 displays the means and standard deviations for the measured properties of all studied materials, including SCG and Weibull parameters. The elastic modulus and Poisson's ratio of PIC were the highest and the lowest, respectively, compared with those of the other materials tested. With respect to $K_{\text {Ic }}(p=0.054)$ and Weibull modulus, no statistically significant differences were detected among materials (Chi-square test for equal shape parameters, $p=0.074$ ). As to inert strength measurements, i.e., measurements made in the absence of slow crack growth, FEL showed the lowest strength, whereas LD showed the highest value. FEL and PIC were the least susceptible to SCG, since their stress corrosion coefficients $(n)$ were significantly higher than those obtained for LD and ZLS. Fig. 5 consists of graphic representations of the strength values obtained for the different materials as functions of the stress rate (inert strength data are included in the graph).

Table 4 - Poisson's ratio, density, elastic modulus $(E)$, fracture toughness $\left(\mathrm{K}_{\mathrm{Ic}}\right)$, coefficient of slow crack growth ( $n$ ), inert strength, Weibull modulus $(m)$, confidence interval of Weibull modulus (CI) and characteristic strength $\left(\sigma_{0}\right)$ of the materials. Means that do not share a letter in the same line are significantly different $(p<0.05)$.

\begin{tabular}{|c|c|c|c|c|}
\hline & PIC & FEL & LD & ZLS \\
\hline Poisson's ratio & $0.28 \pm 0.009^{a}$ & $0.23 \pm 0.02^{b}$ & $0.22 \pm 0.03^{b}$ & $0.23 \pm 0.03^{b}$ \\
\hline Density & 1.87 & 1.67 & 1.65 & 1.60 \\
\hline$E(\mathrm{GPa})$ & $34.7 \pm 2.2^{\mathrm{a}}$ & $48.7 \pm 1.9^{b}$ & $63.9 \pm 4.8^{c}$ & $65.6 \pm 4.1^{c}$ \\
\hline $\mathrm{K}_{\mathrm{Ic}}\left(\mathrm{MPa} \mathrm{m}^{1 / 2}\right)$ & $0.86 \pm 0.27^{a}$ & $0.84 \pm 0.06^{a}$ & $1.23 \pm 0.26^{a}$ & $1.25 \pm 0.79^{a}$ \\
\hline$n$ & $29.1 \pm 7.7$ & $36.6 \pm 6.8$ & $8.4 \pm 0.8$ & $11.2 \pm 1.4$ \\
\hline Inert strength $(\mathrm{MPa})$ & $159.0 \pm 20.6^{a}$ & $116.8 \pm 14.0^{\mathrm{b}}$ & $346.1 \pm 67.3^{c}$ & $207.3 \pm 23.9^{d}$ \\
\hline$m$ & 9.0 & 8.0 & 6.2 & 10.0 \\
\hline CI (lower-upper) & $6.90-11.63$ & $6.28-10.25$ & $4.94-7.75$ & $6.92-14.41$ \\
\hline$\sigma_{0}(\mathrm{MPa}) /$ minimum-maximum values & 167.5/106.6-206.9 & $123.7 / 75.8-158.9$ & $371.4 / 211.7-527.8$ & $217.5 / 151.84-238.61$ \\
\hline
\end{tabular}



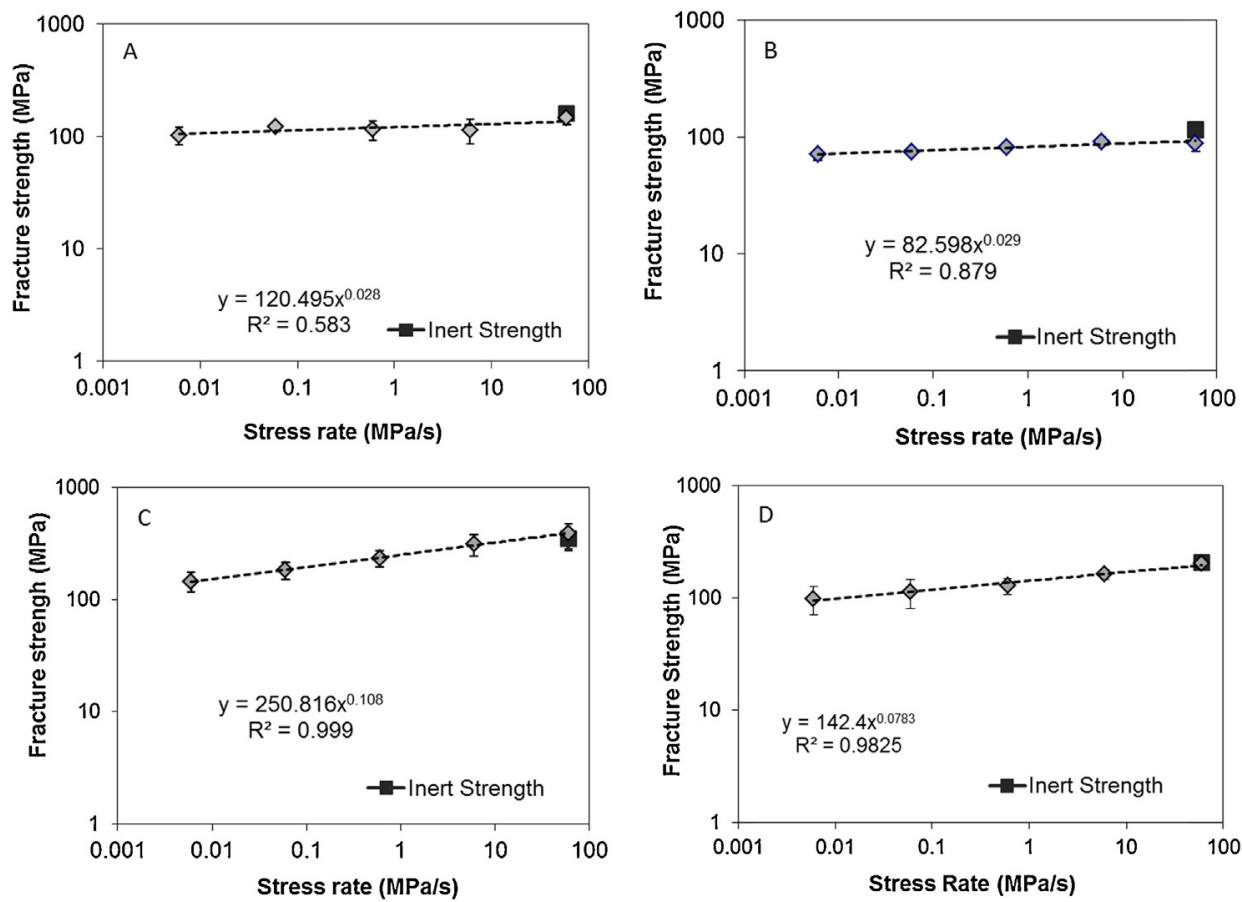

Fig. 5 - (A) PIC, (B) FEL, (C) LD and (D) ZLS. Graphic representations of the means of strength at each stress rate and the inert strength. Steeper regression lines demonstrate higher susceptibility to SCG.
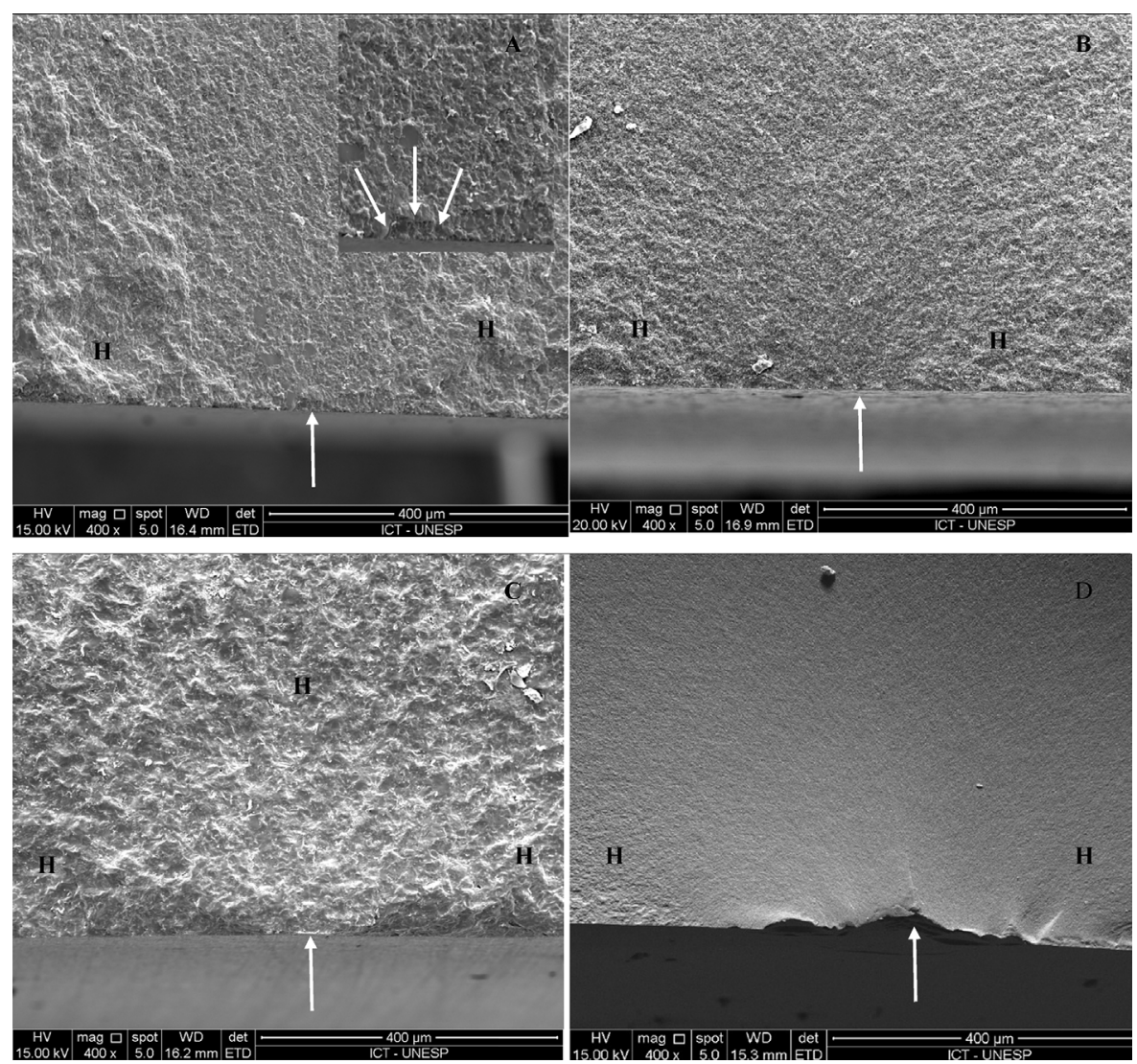

Fig. 6 - SEM images of fractured inert strength specimens. (A) FEL, (B) PIC, (C) LD, (D) ZLS. The arrows indicate the structural flaw on the tensile surface where failure initiated. $H$ stands for "hackles", which were the only noticeable fracture marking surrounding the zone of failure origin. In A, a semi-elliptical flaw led to fracture. 


\subsection{Fractographic analysis}

The fracture origins were mostly structural pores on the surface under tensile stress (Fig. 6). The fractographic analysis of specimens of PIC showed coarse fracture surfaces. Conversely, ZLS showed glassy surfaces and secondary chipping, the reasons for which are unclear.

\section{Discussion}

This paper evaluated the microstructure, reliability and susceptibility to fatigue by stress corrosion of several ceramics processed by CAD-CAM technology. VM II (FEL) showed microstructure based on an aluminum-, potassium- and sodium-based silicate with grains of about $4 \mu \mathrm{m}$, in agreement with findings reported in the literature [8]. The microstructure of PIC is also in agreement with previous studies that described this material as a porous feldspathic ceramic containing polymers infiltrated by capillary action [1,2]. However, in the present investigation both X-ray diffraction and EDS analyses did not detect leucite, although Della Bona et al. [9] inferred that leucite was present in the material, based solely on EDS analysis.

PIC showed elastic modulus value similar to that reported by the manufacturer (around $30 \mathrm{GPa}$ ) [10]; however, the fracture toughness values measured in the present investigation $\left(0.86 \mathrm{MPa} \mathrm{m}^{1 / 2}\right)$ were lower than that reported by the manufacturer $\left(1.5 \mathrm{MPa} \mathrm{m}^{1 / 2}\right)$. The method used by the manufacturer to measure $K_{\text {Ic }}$ was not specified. The fracture toughness value obtained for PIC was similar to that of the feldspathic ceramic. Therefore, the idea that the presence of a polymer network would create toughening mechanisms in the microstructure could not be confirmed. In addition, PIC showed increased susceptibility to SCG (i.e., lower $n$ value) compared with the FEL. This raises the question of whether the polymer is susceptible to water permeation and degradation. However, the calculated density of PIC was the highest among the four materials; therefore, the issue of water penetration in this material requires further investigation.

The glass ceramic containing lithium disilicate (LD) showed needle-like particles with different orientations. Its elastic modulus ( $64 \mathrm{GPa}$ ) and particle size (from 0.5 to $4 \mu \mathrm{m}$ ) also agree with those previously reported in the literature [11]. One could expect that LD would show lower fracture toughness than the lithium silicate reinforced by zirconia (ZLS), because the latter would have an additional toughening mechanism related to the presence of zirconia in the microstructure. However, these two materials showed similar fracture toughnesses and similar Weibull moduli. In fact, the addition of $\mathrm{ZrO}_{2}$ to lithium metasilicate and disilicate did not lead to an increase in strength [12]. Similarly, ZLS did not show higher resistance to crack propagation when compared with LD.

The results of this study showed that susceptibility to slow crack growth was significantly affected by the material's microstructure. No previous studies were found that calculated the SCG parameters of LD for the CAD system, but two reports have estimated $n$ for this material using the hot-pressing technique (Empress 2). These studies showed different values of $n$ for this material, ranging from 17.2 [13] to
28.07 [14]. Thus, one has to take into consideration the variations in the methods used for determining SGC parameters.

In the present study, LD and ZLS showed similar stress corrosion coefficients, which were lower than those obtained for the other materials. These results indicate that the microstructural differences observed between LD and ZLS did not affect their slow crack growth behavior. It is interesting to note that when fast fracture was considered (sigma zero), both materials showed better mechanical behavior than did PIC and FEL. This indicates that the mechanisms affecting slow crack growth are not the same as those that govern fast fracture, because the mode of crack propagation during subcritical growth of the crack is different from that seen during fast fracture [15]. SCG occurs before fast fracture which is why we must be aware of how each material behaves under different stress rates. Yet, from a clinical standpoint, one can say that, for low load zones, PIC and FEL are superior, since their slow crack growth is less affected in the long term; conversely, if the load level is high, LD and ZLS are better candidates for consideration.

A previous SCG study on dental ceramics found that lithium disilicate was the material with the lowest $n$ value [13]. In this case, the alignment of crystals during injection was unable to create a favorable crack path during the biaxial flexure test. From our observations, the crystals were randomly distributed in the glass matrix, and an alignment pattern was not detected. Therefore, we believe that the glass phase quality and the effects of residual thermal stresses between the glass and crystal phases may be responsible for the increased susceptibility to SCG observed for LD. From the fractographic analysis, it was possible to note that the fracture origins were mostly related to structural flaws on the materials' surfaces, and that the fractured surface of the ZLS was indeed very glassy, while that of LD showed a rougher aspect, indicating different crack propagation patterns in these materials. Therefore, more detailed analyses are needed to assess crack propagation in particle boundary regions of these materials.

\section{Conclusions}

The conclusions drawn from our findings were as follows:

a. The four studied ceramics have very different microstructures. The polymer-infiltrated ceramic has two phases, one organic and one inorganic, forming a network. The lithium silicate has elongated grains that are more rounded than the needle-like disilicate grains.

b. PIC does not have a crystalline phase, while LS showed tetragonal zirconia in its composition.

c. The feldspathic and the infiltrated ceramic, as well as the lithium disilicate and lithium silicate, showed similar fracture toughness values. Thus, the polymer present in PIC and the zirconia present in the ZLS did not improve their fracture toughness.

d. The structural reliability (Weibull modulus) of all materials was the same under the condition of fast fracture. Surface flaws were identified as failure origins in all materials.

e. The behavior of the materials in terms of slow crack growth differed significantly. The feldspathic ceramic showed 
the lowest susceptibility to SCG, while lithium silicate reinforced by zirconia and lithium disilicate showed the highest.

\section{Acknowledgments}

The authors acknowledge the São Paulo Research Foundation for financial support (FAPESP \#2013/15541-7).

\section{REFERENCES}

[1] Coldea A, Swain MV, Thiel N. Mechanical properties of polymer-infiltrated-ceramic-network materials. Dent Mater 2013;29(4):419-26.

[2] Coldea A, Swain MV, Thiel N. In-vitro strength degradation of dental ceramics and novel PICN material by sharp indentation. J Mech Behav Biomed 2013;26:34-42.

[3] Guess PC, Zavanelli RA, Silva NR, Bonfante EA, Coelho PG, Thompson VP. Monolithic CAD/CAM lithium disilicate versus veneered Y-TZP crowns: comparison of failure modes and reliability after fatigue. Inter J Prosthodont 2010;23:434-42.

[4] ISO 6872. International organization for standardization, ISO/CD 6872.2 ceramic materials; 1999 http://www.iso.org/ iso/catalogue_detail.htm? csnumber $=41385$.

[5] Strobl S, Rasche S, Krautgasser C, Sharova E, Lube T. Fracture toughness testing of small ceramic discs and plates. J Eur Ceram Soc 2014;34:1637-42.

[6] ASTM C1368-10. Standard test method for determination of slow crack growth parameters of advanced ceramics by constant stress-rate strength testing at ambient temperature. West Conshohocken, PA: American Society for Testing and Materials; 2011 http://www.astm.org/Standards/ C1368.htm.

[7] Guerra RM, Durán I, Ortiz P. FT-IR monomer conversion analysis of UDMA-based dental resins. J Oral Rehab 1996;23:632-7.

[8] Giordano R. Materials for chairside CAD/CAM-produced restorations. J Am Dent Assoc 2006;137:14S-21S.

[9] Della Bona A, Corazza PH, Zhang Y. Characterization of a polymer-infiltrated ceramic-network material. Dent Mater 2014;30:564-9.

[10] Zahnfabrik Vita. Product information number 1780; 2013 https://www.vita-zahnfabrik.com/en/VITA-ENAMIC-10846. html.

[11] Höland W, Schweiger M, Frank M, Rheinberger V. A comparison of the microstructure and properties of the IPS Empress 2 and the IPS Empress glass-ceramics. J Biomed Mater Res 2000;53:297-303.

[12] Apel E, Deubener J, Bernard A, Holand M, Muller R, Kappert $\mathrm{H}$, et al. Phenomena and mechanisms of crack propagation in glass-ceramics. J Mech Behav Biomed Mater 2008;1(4):313-25.

[13] Gonzaga CC, Cesar PF, Miranda Jr WG, Yoshimura HN. Slow crack growth and reliability of dental ceramics. Dent Mater 2011;27:394-406.

[14] Mitov G, Lohbauer U, Rabbo MA, Petschelt A, Pospiech P. Investigations of subcritical crack propagation of the Empress 2 all-ceramic system. Dent Mater 2008;24: 267-73.

[15] Gilbertson LN, Zipp RD. Fractography and materials science, ASTM STP 733. Philadelphia: American Society for Testing Materials; 1981. 